\title{
Poverty Analysis Using Small Area Estimation: An Application to Conservation Agriculture in Uganda
}

Jarrad Farris ${ }^{1}$, Catherine Larochelle ${ }^{2}$, Jeffrey Alwang ${ }^{2}$, George W. Norton ${ }^{2}$ and Caleb King ${ }^{2}$ ${ }^{1}$ Michigan State University, East Lansing, MI, USA

${ }^{2}$ Virginia Tech, Blacksburg, VA, USA

\section{Acknowledgments}

The authors would like to thank Dr. Bradford Mills and an anonymous referee for helpful comments and the staff at AT Uganda, for assistance with data collection. The research was funded by the United States Agency for International Development (USAID) and the Sustainable Agriculture and Natural Resource Management Innovation Lab (SANREM IL). 


\section{Poverty Analysis Using Small Area Estimation: An Application to Conservation Agriculture in Uganda}

\section{Introduction}

Poverty analyses in developing countries rely primarily on estimates of household consumption. Consumption is more stable than income as households can more easily smooth it over time (Deaton and Zaidi, 2002). Although consumption data are an important component of poverty analysis, their collection is time-consuming and expensive. Comprehensive consumption surveys ask households to report consumption of as many as 300 to 400 items (Pape and Mistiaen, 2015).

Due to the importance but high costs of these surveys, projects such as the World Bank's Living Standards Measurement Study (LSMS) aim to increase the availability of high-quality household consumption data for poverty analysis. The LSMS provides unrestricted public access to 107 household surveys from 36 countries (World Bank, 2015). Unfortunately, these high-cost surveys are only representative at high levels of aggregation within a country. For researchers seeking to conduct welfare analysis of small geographic areas, the detailed consumption survey is unlikely to be representative of the area of interest. Recent innovations, such as the 60-minute consumption survey method, which relies on imputation techniques, have been developed to reduce costs of comprehensive consumption data collection (Pape and Mistiaen, 2015). Until these improvements are popularized, however, consumption data representative of small geographic areas will remain relatively rare.

Small area estimation of poverty (SAEp) methods extend the ability to obtain accurate welfare measures for small geographic areas by combining the strengths of multiple datasets. SAEp methods normally combine LSMS, with detailed information on consumption but not 
representative at micro-area levels, with census data, which are representative at low disaggregation levels but do not include information on consumption, to estimate poverty for small geographic areas (Elbers, et al., 2003). Since their seminal work, an expanding literature of in-depth poverty analyses for small geographic areas has emerged (Kijima and Lanjouw, 2003, Okwi, et al., 2003, Tarozzi and Deaton, 2009, Cuong, 2011).

The relevance of the techniques in Elbers, et al. (2003), however, has been masked by their focus on census or large sample. Reliance on census data is restrictive because the microdata (i.e. household-level records) are generally privileged and therefore only accessible to researchers in select organizations. In addition, the infrequent administering of censuses, typically once every decade, but often less frequently, limits the timeframe during which a census can be used for up-to-date poverty analysis even if access to the micro-data is granted. Researchers who apply the ELL methods in the absence of census data typically use surveys that are representative at the same level of aggregation as the original consumption survey (Stifel and Christiaensen, 2007, Daniels, 2011, Christiaensen, et al., 2012, Dang, et al., 2014). Researchers interested in conducting ex-ante or ex-post welfare evaluation of context-specific intervention or technology could also benefit from SAEp methods.

In this study, we apply SAEp methods to obtain welfare estimates for a small geographical area in Uganda and simulate the welfare impacts of a context-specific agricultural technology, conservation agriculture (CA). Our study adds to the literature in three ways. First, it illustrates a new way of combining datasets to obtain reliable poverty estimates for a small area that does not require collecting expensive household consumption data or having access to census data. Our approach consists of conducting a low-cost household survey, which is representative of the small area of interest and combining it with an already-available 
consumption survey, which may not be representative of the small area of interest. This approach is relatively inexpensive because only key variables correlated with consumption need to be collected in the household survey. Moreover, we rely on the freely available LSMS data to measure household consumption. This combination allows researchers to assess poverty impacts while focusing resources on the specifics of the research question of interest, which relates to the second contribution of this study. Previously, SAEp has mainly been motivated as tool to better target welfare and development assistance programs. Our study informs other researchers how SAEp can be used as a tool for ex-ante and ex-post welfare assessment of a context-specific technology or program. Third, we illustrate a simple means of measuring the distributional impacts of a program to promote CA. Our methods, when combined with information on the determinants of CA adoption, will allow program managers to target CA to areas where objectives of environmental and other benefits of CA can be attained along with poverty reduction.

The paper is organized as follows: the next section provides background and context about CA in the study area. Following this, data sources are described. The SAEp method and simulations of the impact of CA adoption on poverty indices are discussed in section 4. Next, results are presented; concluding remarks and implications are discussed in the final section.

\section{Background}

CA is a package of techniques that aims to generate sustained improvements to food security and farm profitability by reversing trends in land degradation. It has also been promoted as a risk mitigation and adaptation strategy to climate change. CA is based on three core principles: minimum or zero tillage, permanent vegetative cover, and diversified crops grown in rotation. 
These practices are expected to be adopted together as a "package" but evidence shows adoption of one or two individual components (Stevenson, et al., 2014; Jalata et al., 2016). Potential benefits of CA led to an increased focus from international agricultural research organizations, such as the U.S. Agency for International Development (USAID), the Food and Agriculture Organization of the United Nations, and the International Maize and Wheat Improvement Center.

While the core principles of CA can be shared, the specifics of the practices must be developed locally to fit agro-climatic and cultural conditions of potentially adopting farmers. Due to the context-specific nature of the technology, international agricultural research organizations collaborate with local partners to test and adapt CA practices to local conditions. In Uganda, USAID-supported researchers worked with Appropriate Technology Uganda, a local NGO, to develop, test, and extend CA core principles in two districts (SANREM, 2013). This study focuses on Tororo district of Uganda and efforts to promote CA in the area.

Tororo is located in the lowland of Uganda's eastern region. Subsistence farming is the main source of livelihood for about $80 \%$ of households (UBOS, 2014). The agricultural system is dominated by annual crops, such as maize, cassava, groundnut, millet, and beans, which are grown twice a year. Poor sandy loam soils and variable rainfall limit the area's agricultural potential. These constraints, combined with the district's high population density (UBOS, 2014), resulted in land degradation. By concentrating on the linkages between soil fertility and farmer livelihoods, CA practices were marketed as win-win solutions that harmonize environmental and economic concerns (SANREM, 2013). The CA package evaluated in Tororo consisted a maizebean intercropped system with zero or minimum tillage and, as alternative weed control methods, herbicide application and strip intercropping with mисипа (a legume used as a crop cover). Evaluation of these practices was conducted on-station and on-farm during four seasons. 
Conservation agriculture is expected to benefit farmers through several pathways. First, the enhanced maize-bean rotations have been optimized and will increase incomes directly. Second, CA is expected, over time, to increase soil health and raise productivity. Permanent ground cover, such as that provided by mucuna, suppresses weeds and, due to its nitrogen fixing property, improves soil fertility. The crop cover also improves soil moisture. After a few seasons planting mucuna within a maize or maize-bean intercropped system, crop productivity normally increases. Third, in the shorter run, because CA eliminates tillage, labor costs associated with tillage operations are reduced; even in the absence of yield benefits, costs per unit of output will fall. The CA package for Tororo does not involve expensive machinery and the inputs are no costlier than current inputs. As a result, adoption should be independent of household wealth, and poor farmers, as well as those that are better off, should benefit. It is hoped that the combination of these factors will reduce poverty as the technology is widely adopted.

Recent evidence on CA from Africa has been promising. In Zambia, CA improves maize output and reduces household poverty (Abdulai, 2016), and in Ethiopia, minimum tillage, a key part of the CA package, increases maize yield and decreases labor use (Jalata et al., 2016). Incorporation of improved maize varieties into rotations, another CA component, has shown to improve yields and reduce poverty in numerous African countries (Mason and Smale, 2013; Zeller et al., 1998; Zeng et al., 2015).

\section{Data}

We use the 2011/2012 LSMS-Integrated Surveys on Agriculture (LSMS-ISA) for Uganda to obtain precise information on household consumption expenditures. The sample is nationally representative, representative of rural and urban areas, and of Uganda's main four regions 
(North, East, West, and Central regions). Despite the detail of the LSMS-ISA consumption data, this dataset alone cannot provide a reliable estimate of rural poverty in Tororo district. To overcome this limitation, a representative household survey in Tororo was conducted.

\subsection{LSMS-ISA Household Consumption}

The LSMS-ISA, which includes household, agriculture, and community questionnaires, collected data from 2,716 Ugandan households on an extensive range of topics including household demographics, education, health, food and non-food consumption, asset ownership, agricultural landholding, input use, crop production, and livestock ownership. This study makes use of the household and agriculture questionnaires. Household welfare is estimated using data from the section on household consumption expenditures. Following methods outlined in Deaton and Zaidi (2002), annual household consumption is estimated by summing the annual values of food consumption, non-durable and semi-durable goods, and the user cost of durable goods ${ }^{1}$. Household consumption per capita, our welfare measure, is estimated by dividing the aggregate consumption measure by the number of people present for at least half of the household's meals during the seven-day food recall period. This approach accounts for the possibility that not all household members may have been present during the seven-day food recall period.

Other sections of the household questionnaire, such as household demographics, housing conditions, water and sanitation, and household assets, are used in the estimation of per capita household consumption (explained below). Given that the welfare analysis is conducted for the rural households in Tororo, the model explaining household consumption also includes a few variables related to agricultural assets ownership obtained from the agriculture survey.

\subsection{Tororo Household Survey}

\footnotetext{
${ }^{1}$ The aggregation includes expenditures on beverages and tobacco, but excludes the consumption of items related to medical care, as suggested in in Deaton and Zaidi (2002).
} 
A representative household survey of the Tororo district was conducted in July and August 2014. Since this survey was to be linked with the LSMS-ISA, several steps were taken before and during the design of the questionnaire to ensure compatibility between the two surveys. Models of per capita consumption as a function of household characteristics were first estimated to identify household variables in the LSMS-ISA data that best predict per capita consumption $^{2}$. Previous SAEp applications guided the choice of variables (Okwi, et al., 2003, Cuong, 2011, Daniels, 2011). These findings dictated which questions to include in the Tororo household survey (THS) questionnaire. This approach has the advantage of reducing the amount of information collected in the household survey, which in turn reduces the costs of data collection. The THS questionnaire was also designed to mimic as closely as possible the LSMSISA questionnaire. For instance, a household and its members were defined using the same criteria as in the LSMS-ISA and questions were phrased in the same manner wherever possible.

The THS survey requested information on household and member characteristics, such as age, gender and education levels, housing conditions, ownership of major durable goods and farming assets, agricultural practices, input use, use of agricultural loans, etc. In addition, the THS included questions on CA adoption, adapted from previous CA surveys conducted in the district (Vaiknoras, et al., 2015). The survey team also conducted focus group discussions with key informants in each village. Information was gathered on village characteristics, adoption of $\mathrm{CA}$, and yield, production costs, and price for the main crops in the village.

A stratified, multistage clustered sampling design was employed. Sub-counties were the primary sampling units (PSUs), villages were the secondary sampling units (SSUs), and households were the ultimate sampling units (USUs). Due to the focus on rural poverty and

\footnotetext{
${ }^{2}$ To reduce potential "noise" in predicted consumption estimates (explained below), the vast majority of selected variables were significant at the five percent level or lower.
} 
agriculture, the district's three urban municipalities were excluded from the sample frame. The sample includes 480 households located across 24 villages dnd 6 sub-counties. This surveybased population estimate is 88,993 households, which is very close to the preliminary 2014 Population Census estimate of 89,930 households released in November 2014 (UBOS, 2014).

To improve the representativeness of the THS in light of the updated census strata population estimates, post-stratification adjustment factors (PSAFs) were calculated by dividing the 2014 Census strata population fractions by their THS sampling fractions. The strata sampling fractions were adjusted to match their 2014 Census strata population fractions by multiplying each household weight by its stratum's PSAF.

\section{Methods}

In order to obtain precise measures of poverty and inequality in Tororo district, the THS is linked to the LSMS-ISA through SAEp methods. Then, the effects of CA-induced farm profit increases on welfare are simulated for different scenarios about the profitability and adoption level of CA in Tororo district. These scenarios are developed by combining data from on-station and on-farm trials, community focus groups and the THS.

\subsection{Small area estimation of poverty}

In order to estimate welfare in Tororo district, the following linear mixed effects model, adapted from ELL $(2002,2003)$, is specified:

$$
\ln \left(y_{c h}\right)=x_{c h} \beta+\eta_{c}+\varepsilon_{c h}
$$

where $\ln \left(y_{c h}\right)$ is the natural log of the per capita consumption estimated from the LSMS-ISA. The subscript $c h$ represents a given rural household $h$ in a cluster $c$ in the eastern region of Uganda. A cluster describes a group of households located in the same enumeration area or 
village. The fixed portion of the right-hand side (RHS) of (1) consists of two vectors: $x_{c h}$ and $\beta$. $x_{c h}$ is a vector of household characteristics correlated with $\ln \left(y_{c h}\right)$ consisting of household demographics, housing characteristics, and ownership of durable goods and farm assets. $\beta$ is a vector of parameters, including an intercept, to be estimated. The remaining two terms of (1), $\eta_{c}$ and $\varepsilon_{c h}$, are the cluster-specific and household-specific random effects respectively. These decomposed error components are assumed to be independent ${ }^{3}$.

The consistency of the subsequent analysis rests on several key assumptions. First, it is assumed that the Measurement of Predictors (MP) and the Area Homogeneity (AH) assumptions typical of SAEp hold (Tarozzi and Deaton, 2009). The MP assumption requires that the household characteristics be measured in the same way in both the LSMS-ISA and THS. As noted, the THS questionnaire and household definition were developed specifically to mimic the LSMS-ISA, limiting measurement differences that can surface. However, the LSMS-ISA is significantly longer than the THS, which could cause measurement errors (Tarozzi and Deaton, 2009). In a typical SAEp analysis, the equivalence of the explanatory variable candidates would be assessed by comparing survey and census means at the regional level. Since this study uses a representative survey of Tororo district in place of census data, it is impossible to make regional mean comparisons and the analysis rests on the assumption that MP holds.

Along with the MP assumption, the $\mathrm{AH}$ assumption requires that the conditional distribution of household consumption per capita given household characteristics be the same for rural households in Tororo district and rural households in the eastern region. Additionally, this conditional distribution must be stable over the two time periods. That is, the $\beta$ vector of parameters in (1) must be the same in the rural eastern region in 2011/2012 as it is in rural

\footnotetext{
${ }^{3}$ The assumption of independence of the two components of the error term can be justified since households in a given village are selected independently of the village characteristics.
} 
Tororo district in 2014 (Tarozzi and Deaton, 2009, Cuong, 2011, Daniels, 2011). While AH is a standard assumption of SAEp, findings from Tarozzi and Deaton (2009) suggest that if it does not hold in practice then the precision of SAEp estimates will be overstated. They conclude that the necessity of both MP and AH should be emphasized when conducting SAEp. In this study, only rural households in the eastern region are included when estimating the parameters in (1), rather than a larger, more heterogeneous group, which increases the likelihood that $\mathrm{AH}$ holds. Furthermore, the relatively short time gap between the two surveys (approximately two years) increases the likelihood that the conditional distribution is stable. A two-year (or longer) time gap is common in past studies employing SAEp methods (Kijima and Lanjouw, 2003, Elbers, et al., 2008, Christiaensen, et al., 2012); in our shorter period, the likelihood that the conditional distribution is stable is higher than in these studies.

Along with MP and $\mathrm{AH}$, the estimates rely on the assumption that the LSMS-ISA and the THS are representative of rural households in the eastern region and rural households in Tororo district respectively (Cuong, 2011, Daniels, 2011). The LSMS-ISA was designed specifically to be representative of the rural and urban portions of each of Uganda's four regions (UBOS, 2013). Similarly, the THS was designed specifically to be representative of rural households in Tororo. Thus, the representativeness assumption is expected to hold in this study.

Returning to the linear mixed effect model specification in (1), $\eta_{c}$ and $\varepsilon_{c h}$, the clusterspecific and household-specific random effects respectively, pose special challenges for predicting household consumption. The LSMS-ISA randomly sampled 58 clusters in the rural portion of the eastern region, which represent a random draw from the larger population. Within each cluster, an average of $\sim 10$ households were randomly selected for a total of 565 households (UBOS, 2013). The challenge is that households within a given cluster may be related in 
unmeasured ways. If present, such intra-class correlation reduces the amount of unique information present in each household observation and the total error can no longer be thought of as independent. Furthermore, because SAEp makes out-of-sample predictions for households in non-sampled clusters, each cluster cannot simply be modeled as a fixed effect.

The model in (1) accounts for intra-class correlation by decomposing the total model error into two independent, nested random effects. The cluster-specific random effect, $\eta_{c}$, allows for a portion of the model error to be correlated for households within the same cluster. By AH, the values of the $\beta$ vector are assumed to be homogenous throughout all clusters in the eastern region; the incorporation of $\eta_{c}$, however, allows for cluster-specific heterogeneity in the realized intercept (Tarozzi and Deaton, 2009). The nested household-specific random effect then allows each household to further deviate from its cluster in a unique way. Greene (2012, p.412) notes that the "parameters of the random effects model can be estimated consistently, though not efficiently by ordinary least squares (OLS)." Therefore, working towards the derivation of the random effects, the following simpler model is estimated using OLS, taking into account survey weights:

$$
\ln \left(y_{c h}\right)=x_{c h} \beta+u_{c h}
$$

where $u_{c h}$ is the combined model error. The estimated residuals from (2) are then decomposed into the cluster-specific and household specific components:

$$
\hat{u}_{c h}=\hat{\eta}_{c}+\hat{\varepsilon}_{c h}
$$

where the estimate of the cluster-specific random effect, $\hat{\eta}_{c}$, is the average total residual of the sampled households in a particular cluster. Specifically:

$$
\hat{\eta}_{c}=\frac{1}{M_{c}} \sum_{h=1}^{M_{c}}\left(\ln \left(y_{c h}\right)-\ln \left(\widehat{y_{c h}}\right)\right)
$$


where $M_{c}$ is the number of sampled households in a given cluster $c$ and $\ln \left(\widehat{y_{c h}}\right)$ is the fitted value from (2). The estimate of the household-specific random effect becomes:

$$
\hat{\varepsilon}_{c h}=\hat{u}_{c h}-\hat{\eta}_{c}
$$

$\hat{\varepsilon}_{c h}$ is therefore a measure of how far away a particular household is from the average residual in its cluster.

Having decomposed the estimated total residuals into the two component parts, the next challenge is to generate estimates of $\sigma_{\eta}^{2}$ and $\sigma_{\varepsilon}^{2}$, the variances of $\eta$ and $\varepsilon$ respectively. It is plausible that these variances could be heteroskedastic. Greene (2012) references the possibility of heteroskedasticity in the cluster-specific random effect before describing the "insurmountable problem" associated with empirically estimating it. In essence, the problem is that since every household in a given cluster shares the same cluster-specific effect, there are only 58 unique observations on $\eta$. Therefore, just as in Elbers, et al. (2003), this study assumes that the clusterspecific random effect is homoskedastic.

As $\eta$ and $\varepsilon$ are independent, the variance of the total estimated residual from (2) is simply the sum of $\sigma_{\eta}^{2}$ and $\sigma_{\varepsilon}^{2}$. Therefore, the general approach to estimating $\sigma_{\eta}^{2}$ is summarized as:

$$
\begin{aligned}
\sigma_{\mu}^{2} & =\sigma_{\eta}^{2}+\sigma_{\varepsilon}^{2} \\
\Rightarrow \sigma_{\eta}^{2} & =\sigma_{\mu}^{2}-\sigma_{\varepsilon}^{2}
\end{aligned}
$$

where $\sigma_{\mu}^{2}$ is the variance of the total estimated residual from (2). A complicating factor in the estimation of (6) is that the sums of the weighted observations in each cluster are not equal. That is, the observations in one cluster may have larger sample weights than the observations in another cluster. This study applies the method derived by Elbers, et al. (2003) to account for unequal cluster weights in the estimation of $\sigma_{\eta}^{2}$. Adapted from Appendix I of Elbers, et al. (2002), $\sigma_{\eta}^{2}$ is estimated as follows: 


$$
\hat{\sigma}_{\eta}^{2}=\max \left\{\frac{\left(\sum_{c=1}^{C} w_{c}\left(\hat{\eta}_{c}-\overline{\hat{\mu}}\right)^{2}\right)-\left(\sum_{c=1}^{C} w_{c}\left(1-w_{c}\right) \frac{\sum_{h=1}^{M_{c}}\left(\hat{\varepsilon}_{c h}-\overline{\hat{\varepsilon}}_{c}\right)^{2}}{M_{c}\left(M_{c}-1\right)}\right)}{\sum_{c=1}^{C} w_{c}\left(1-w_{c}\right)} ; 0\right\}
$$

where $C$ is the number of clusters, $w_{c}$ is the weight of cluster $c, \hat{\eta}_{c}$ is the cluster-specific random effect for cluster $c$ from (4), $\overline{\hat{\mu}}$ is the overall average of the total residuals from (3), $M_{c}$ is the number of sampled households in cluster $c, \hat{\varepsilon}_{c h}$ is the household-specific random effect for household $h$ from (5), and $\overline{\hat{\varepsilon}_{c}}$ is the average of the household-specific random effects for cluster $c$ from (5). The weight of cluster $c$ is given by:

$$
w_{c}=\frac{\sum_{h=1}^{M_{c}} \lambda_{h}}{\sum_{h=1}^{N} \lambda_{h}}
$$

where $\lambda_{h}$ is the sample weight of household $h$ multiplied by its household size and $N$ is the number of sampled households.

The more than 500 unique observations on $\varepsilon$ permit the modeling of heteroskedasticity in this component. In order to consistently estimate the heteroskedastic variance of $\varepsilon_{c h}$, any residual cluster effects are first purged from $\hat{\varepsilon}_{c h}$ by regressing $\hat{\varepsilon}_{c h}$ on a series of dummy variables corresponding to all but one of the 58 clusters. The residuals from this regression become the purged $\hat{\varepsilon}_{c h}$ used throughout the estimation of $\sigma_{\varepsilon_{c h}}^{2}$. The household-specific variance is then modeled using the modified logistic form proposed by Elbers, et al. (2003):

$$
\sigma_{\varepsilon_{c h}}^{2}=A p_{c h}+B\left(1-p_{c h}\right)
$$

where $A$ and $B$ are the upper and lower variance bounds respectively and $p_{c h}$ is:

$$
p_{c h}=\left[\frac{e^{z_{c h} \alpha}}{1+e^{z_{c h} \alpha}}\right]
$$

where $z_{c h}$ is a vector of $k$ observable characteristics for a given household $h$ and $\alpha$ is a vector of $k$ parameters. Where a given household's predicted variance falls on the interval between $A$ and 
$B$ depends on the household's $z_{c h}$ vector of characteristics and the estimate of $\alpha$. To simplify estimation of (9), $\hat{\varepsilon}_{c h}{ }^{2}$ is taken as an unbiased estimate of the household-specific variance and the upper bound, $A$, is set as 1.05 times the max $\hat{\varepsilon}_{c h}{ }^{2}$. Similarly, the lower bound, $B$, is set at 0 . This allows, through the rearrangement of terms, an estimation of the $\alpha$ vector in (9) via OLS:

$$
\ln \left(\frac{\hat{\varepsilon}_{c h}^{2}}{A-\hat{\varepsilon}_{c h}{ }^{2}}\right)=z_{c h} \alpha+v_{c h}
$$

where $v_{c h}$ is a disturbance term such that $\mathrm{E}\left(v_{c h} \mid z_{c h}\right)=0$. For initial estimation of $(11), z_{c h}$ is identical to $x_{c h}$ from (1). Any characteristics with coefficient estimates not significant at the $10 \%$ level are then dropped from $z_{c h}$ and (11) is re-estimated using the pared-down $z_{c h}$. Using the estimated $\hat{\alpha}$ vector from (11) and the assumed $A$ and $B$, the variance of each household's $\hat{\varepsilon}_{c h}$ is predicted using (9).

Having estimated $\hat{\sigma}_{\eta}^{2}$ and $\hat{\sigma}_{\varepsilon_{c h}}^{2}$, the estimated variance-covariance matrix in (2) for the households in a given cluster $c$ is given by:

$$
\Sigma=\left[\begin{array}{cccc}
\hat{\sigma}_{\varepsilon_{c h}}^{2}+\hat{\sigma}_{\eta}^{2} & \hat{\sigma}_{\eta}^{2} & \ldots & \hat{\sigma}_{\eta}^{2} \\
\hat{\sigma}_{\eta}^{2} & \hat{\sigma}_{\varepsilon_{c h}}^{2}+\hat{\sigma}_{\eta}^{2} & \ldots & \hat{\sigma}_{\eta}^{2} \\
\vdots & \vdots & \ddots & \vdots \\
\hat{\sigma}_{\eta}^{2} & \hat{\sigma}_{\eta}^{2} & \ldots & \hat{\sigma}_{\varepsilon_{c h}}^{2}+\hat{\sigma}_{\eta}^{2}
\end{array}\right]
$$

Since all the error components are assumed to be independent, the covariance between households in different clusters is zero. Therefore, the full estimated variance-covariance matrix for all $N$ observations is given by:

$$
\Omega=\left[\begin{array}{cccc}
\Sigma & 0 & \ldots & 0 \\
0 & \sum & \ldots & 0 \\
\vdots & \vdots & \ddots & \vdots \\
0 & 0 & \ldots & \Sigma
\end{array}\right]
$$

where the $\sum$ matrices for each cluster are as defined in (12) (Greene, 2012). In the presence of non-spherical errors, Feasible Generalized Least Squares (FGLS) can provide more efficient 
estimates of the $\beta$ vector in (2) than OLS (Greene, 2012). As this would allow for tighter predictions of household consumption per capita, the $\beta$ vector from (2) is re-estimated using the estimated variance-covariance matrix and FGLS. To guard against potential violations of the error component assumptions used to derive the estimated $\Omega$, village-level cluster robust standard errors are reported along with the estimated FGLS coefficients.

Consistent and efficient estimation of the $\beta$ vector and the associated fitted values, $x_{c h} \hat{\beta}$, is not sufficient for estimating poverty since the FGT poverty indices are functions of the distribution of $y_{c h}$ and not its conditional expectation (Tarozzi and Deaton, 2009). Therefore, in order to estimate district-level rural poverty indices, the distribution of $y_{c h}$ is simulated. These simulations are conducted using a modified version of residual bootstrapping which takes into account the uncertainty in estimating the parameters, the within-cluster correlation of the error terms, and the heteroskedasticity in the household-specific error component (Elbers, et al., 2003, Tarozzi and Deaton, 2009).

Before beginning these simulations, new sets of the cluster-specific and householdspecific random effects are prepared by decomposing the residuals from the FGLS estimation into $\hat{\eta}_{c}$ and $\hat{\varepsilon}_{c h}$ as in (3). The estimated $\hat{\alpha}$ vector from (11) and the set of $\hat{\sigma}_{\varepsilon_{c h}}^{2}$ from (9) are then re-estimated using this new set of decomposed residuals and the previously described methods. The $\hat{\varepsilon}_{c h}$ are standardized based on the new predictions of $\sigma_{\varepsilon_{c h}}^{2}$ as follows:

$$
\hat{\varepsilon}_{c h}^{*}=\frac{\hat{\varepsilon}_{c h}}{\sigma_{\widehat{\varepsilon}_{c h}}}
$$

where $\sigma_{\hat{\varepsilon}_{c h}}$ is the square root of the predicted household-specific variance for a given household $h$. The purpose of this transformation is to make each $\hat{\varepsilon}_{c h}$ comparable by rescaling it based on its estimated variance. These newly prepared sets of $\hat{\varepsilon}_{c h}^{*}$ and $\hat{\eta}_{c}$ are drawn from throughout the 
simulation procedure (Elbers, et al., 2003). After these preparations, the steps for each $r^{\text {th }}$ simulation are as follows:

a) To account for the uncertainty in estimating $\beta$ and $\alpha$, new parameter vectors $\hat{\beta}^{r}$ and $\hat{\alpha}^{r}$ are drawn from their asymptotic, normal distributions using the point estimates and variance-covariance matrices from the FGLS estimation of (2) and the accompanying estimation of (11).

b) For each of the 24 sampled clusters in the THS, a random cluster-specific effect, $\hat{\eta}_{c}^{r}$, is drawn with replacement from the prepared set of all $\hat{\eta}_{c}$ with the probability of selection proportional to its cluster weight from (8).

c) For each of the 480 sampled households in the THS, a random standardized householdspecific effect, $\hat{\varepsilon}_{c h}^{* r}$, is drawn with replacement from the set of all $\hat{\varepsilon}_{c h}^{*}$.

d) The heteroskedastic variances of the household-specific effects, $\hat{\sigma}_{\varepsilon_{c h}}^{2}$, are predicted based on the model of heteroskedasticity in (9), each household's $z_{c h}$ vector of characteristics, the drawn $\hat{\alpha}^{r}$, and the assumed $A$ and $B$ bounds.

e) Estimates of the non-standardized household-specific effects, $\hat{\varepsilon}_{c h}^{r}$, are generated by multiplying each household's drawn $\hat{\varepsilon}_{c h}^{* r}$ by the square root of its associated result from step (d).

f) Simulated values of household consumption per capita, $y_{c h}^{r}$, are generated as:

$$
y_{c h}^{r}=\exp \left(x_{c h} \hat{\beta}^{r}+\hat{\eta}_{c}^{r}+\hat{\varepsilon}_{c h}^{r}\right)
$$

g) The headcount poverty is estimated as:

$$
\begin{aligned}
& \hat{P}_{0}^{r}=\frac{1}{N} \sum_{i=1}^{480}\left[\frac{z-y_{c h}^{r}}{z}\right]^{\delta=0} \\
& * 1\left[y_{c h}^{r}<z\right]
\end{aligned}
$$


where $\hat{P}_{0}^{r}$ is the $r^{\text {th }}$ simulated headcount poverty conditional on the THS, N $(=480)$ is the number of sampled households, $z$ is the poverty line, and $y_{c h}^{r}$ is the simulated result from (15) for the $i^{\text {th }}$ household weighted by its sampling weight.

h) Step (g) is repeated with $\delta=1$ to generate $\hat{P}_{1}^{r}$, the $r^{\text {th }}$ simulated poverty depth conditional on the THS.

i) Step $(\mathrm{g})$ is repeated with $\delta=2$ to generate $\hat{P}_{2}^{r}$, the $r^{\text {th }}$ simulated poverty severity conditional on the THS.

These simulation steps are repeated 10,000 times to generate 10,000 estimates of each poverty index based on simulated household consumption per capita. The expected values of the poverty indices conditional on the THS are calculated as:

$$
\bar{P}_{\delta}=\frac{1}{R} \sum_{r=1}^{R} \hat{P}_{\delta}^{r}
$$

where $\mathrm{R}$ is the total number of replications, $\hat{P}_{\delta}^{r}$ is the $r^{\text {th }}$ simulated poverty estimate conditional on the THS, and $\delta$ is 0,1 , or 2 for poverty headcount, depth, or severity respectively. The estimated variance of each $\bar{P}_{\delta}$ is:

$$
\operatorname{Var}\left(\bar{P}_{\delta}\right)=\frac{1}{R} \sum_{r=1}^{R}\left(\hat{P}_{\delta}^{r}-\bar{P}_{\delta}\right)^{2}
$$

Due to the form of residual bootstrapping described above, this estimated variance takes into account the uncertainty in estimating the parameters along with the realization of the unobserved components of household consumption (Elbers, et al., 2003). The 95\% confidence intervals for each poverty measure are estimated directly from their empirical distributions by calculating the $2.5^{\text {th }}$ and $97.5^{\text {th }}$ percentiles of the 10,000 estimates. 
We use the international poverty line of $\$ 1.25$ at 2005 Purchasing Power Parity (PPP), which is just $\$ 0.02$ lower than Uganda's official poverty line (Ravallion, et al., 2009). Use of the international line facilitates cross-country comparisons without losing applicability for policy makers and researchers in Uganda. Following standard practice, \$1.25 per capita per day at 2005 PPP is converted to local currency by applying Uganda's 2005 PPP conversion factor for private consumption ${ }^{4}$. The converted 2005 poverty line is deflated to 2012 using the International Monetary Fund's official consumer price index for Uganda (World Bank, 2016a). Due to its stochastic component, the predicted consumption for a given household in relation to the poverty line may not be identical for all simulations. Thus, we consider a household to be poor if its predicted consumption falls below the poverty line in more than $70 \%$ of the 10,000 simulations.

\subsection{Simulations of poverty reductions from CA adoption}

The objective is to assess "best case" scenarios for the poverty impacts of CA adoption in Tororo. CA adoption is expected to influence yield and production costs (explained below), where the net effect of CA on farm profits $^{5}$ is the combination of these two changes. We measure the annual change in farm profitability, $\Delta \pi_{c h}$, for household $h$ in cluster $c$ as

$$
\Delta \pi_{c h}=2\left(\gamma l_{c h}\right)
$$

where $\gamma$ is the per-acre change in farm profits and $l_{c h}$ is acres cultivated under CA in a cropping season. Since there are two cropping seasons per year in Uganda, $\gamma l_{c h}$ is multiplied by two to obtain the annual change in farm profitability associated with CA. Equation (19) relies on the assumptions that changes in farm profits from CA adoption and quantity of land under CA are

\footnotetext{
${ }^{4}$ The conversion factor of 612.70 Ugandan shillings per international dollar is based on estimates from the 2011 round of the International Comparison Program (World Bank, 2016b).

${ }^{5}$ Since CA adoption in Tororo is not expected to generate large short-term yield increases, changes in output price due to adoption is assumed to be zero.
} 
identical in both seasons and that per-acre change in farm profits is constant across households. Adoption of and profits from CA are assumed to be invariant to land ownership status.

Through higher yield and lower production costs, adoption of CA is expected to directly and indirectly impact household consumption. Higher yields can directly boost household consumption. Lower production costs, like market sales, increase cash available to spend on food and non-food items. While adoption of CA can influence consumption through several channels, it is assumed that a change in farm profit translates into an equal change in household consumption expenditure.

To assess the effect of CA adoption on poverty, the annual increase in farm profit, $\Delta \pi_{c h}$, is added to the corresponding predicted household consumption estimate in (15) of simulation step (f). For non-poor households, $y_{c h}^{r}$ remains unchanged. The rest of the simulation procedure is repeated as before. Using the same sets of draws of $\hat{\beta}^{r}, \hat{\alpha}^{r}, \hat{\eta}_{c}^{r}$, and $\hat{\varepsilon}_{c h}^{* r}$ as the initial 10,000 simulations, the impact of the consumption changes on the estimated rural poverty indices is assessed. This process is repeated at varying levels of per-acre changes in the farm profits $(\gamma)$ and acres under $\mathrm{CA}\left(l_{c h}\right)$ in order to assess the sensitivity of the poverty impacts to different profitability and adoption scenarios.

\subsection{Conservation agriculture profitability and adoption scenarios}

Profitability of locally adapted CA is estimated by combining data from on-station and on-farm trials with findings from the village focus group discussions conducted during the THS $^{6}$. The yield analysis of the on-station and on-farm trial data for the first two years (four seasons) showed no significant difference in yields from CA compared to conventional practices

\footnotetext{
${ }^{6} \mathrm{CA}$ was not widely adopted at the time of the THS so yield and costs of production differences could not be estimated using the household survey. In an ex-ante case, this is likely to be true. After substantial adoption, a THS-like survey could be used to measure changes from CA after accounting for the endogeneity of adoption.
} 
(SANREM, 2013). Households may still experience positive net returns from CA if the technology lowers costs of production. In fact, on-station estimates show a decrease in production costs of approximately 85,500 Ugandan Shillings (UGX) or 34.14 USD per-acre perseason for CA relative to conventional practices (Grace Tino, personal communication, April 2015). This reduction is primarily driven by land preparation cost savings of 240,000 UGX (95.85 USD) per-acre due to zero tillage. Herbicide application and planting mucuna as cover crop increased on-station production costs by 97,000 UGX (38.74 USD) and 57,500 UGX (22.96 USD) per-acre per-season, respectively.

Since experimental station conditions are not representative of the reality faced by smallholding farmers, the on-station partial budget framework is adapted based on village focus group findings to reflect the production costs of an average farmer in Tororo district. We maintain the assumption of no change in yield and discuss two scenarios about changes in production costs between the two systems.

Focus group discussions reveal that on-station land preparation costs are higher than what they are in a non-research setting. In most villages, the main method of land preparation is oxen. As ownership of oxen and ox ploughs is scarce, land preparation is primarily hired. Across the 24 sampled villages, land preparation cost averaged about 60,000 UGX per-acre per ploughing and households generally plough twice ${ }^{7}$. Therefore, adoption of no-till would decrease production costs by 120,000 UGX (47.92 USD) per-acre per-season. Labor used in herbicide application and mucuna planting and relaying is also re-evaluated at the average agricultural labor daily wage. This results in additional production costs of 118,500 UGX (47.32 USD) for

\footnotetext{
${ }^{7}$ On-station land preparation costs are also based on two ploughings per-season.
} 
herbicide application and mucuna under farmer conditions. Under these assumptions, CAinduced per-acre farm profit increase is a modest 1,500 UGX (0.60 USD) per-acre per-season.

In Uganda, like in many developing countries, the custom is to save harvested seeds to be used as planted material the next season. Assuming that farmers use recycled mucuna seeds could provide significant cost savings. In the second scenario, we estimate the opportunity cost of using recycled mucuna seeds at $75 \%$ of the seed's original $\operatorname{costs}^{8}$. Based on this assumption, the increase in per-acre farm profit due to CA adoption is 9,000 UGX (3.59 USD) per-season. For both profitability scenarios, we make three assumptions about the level of CA adoption, resulting in a total of six scenarios. Using THS data, we first assume that households will allocate 50 and 75 percent of their cultivated land to CA. Then, all poor households are assumed to allocate one acre to CA.

\section{Results and Discussion}

\subsection{Small area estimation of poverty}

Household consumption per capita among rural households in eastern Uganda, computed using the LSMS-data, averages 623,070 UGX (248.77 USD) annually. This is slightly above the adjusted international poverty line of 567,475 UGX (226.58 USD). The resulting poverty headcount, depth, and severity are $0.5627,0.1758$ and 0.0751 respectively (table 1 ). More than half of the for rural population in the eastern region has consumption expenditure below the international poverty line. The estimated rural poverty depth translates to an average poverty gap of approximately $\$ 0.22$ per day at 2005 PPP.

\footnotetext{
${ }^{8}$ This is a conservative estimate since mucuna seeds are not for human consumption.
} 
Per capita household consumption, as defined in equation (2), is modeled as a function household composition (household size, adult share), housing characteristics (type of floor, source of drinking water, access to electricity), ownership of durable goods (cell phone, motorcycle), farm assets (land owned, pigs), and household member education levels using the THS data. The model has an adjusted $\mathrm{R}^{2}$ of 0.455 , which is within the range of previous applications of SAEp. For examples, Okwi, Emwanu, and Hoogeveen (2003), who estimated a consumption model for eastern rural Uganda, obtained an adjusted $\mathrm{R}^{2}$ of 0.34 ; the adjusted $\mathrm{R}^{2}$ of the consumption model for Uganda in Daniels (2011) was 0.247. Coefficients and standard errors of the estimated regression ${ }^{9}$ on household consumption are reported in table 2.

Although the primary purpose of this regression is prediction and any interpretation of the parameter estimates should be tentative, the signs and magnitude of estimated coefficients are intuitive. For instance, estimated coefficients of cell phone and motorcycle ownership are positively associated with household consumption, while the magnitude of the coefficient for motorcycle ownership is three times larger than that for cell phone ownership (table 2). Formal education is positively correlated with household consumption and the correlation increases at higher education levels. Using this model and the THS data, household consumption and FGT poverty indices in Tororo district are predicted by applying the SAEp method.

The cumulative distribution function (CDF) of predicted per capita household consumption for rural Tororo district is depicted in figure 1. This CDF provides a visualization of the 4.8 million simulated consumption values $(10,000$ predictions for each of the 480 sampled households). The majority of household consumption predictions falls below the international poverty line, resulting in the estimated poverty incidence of $56.49 \%$ (table 1 ). This estimate is

\footnotetext{
${ }^{9}$ One outlying observation was omitted from the regression; its consumption per capita was 2.4 times the second largest estimated consumption per capita value, resulting in undue influence on the fitted regression line.
} 
within half a percent of the poverty estimate for the rural eastern region as a whole. The estimated poverty depth and severity indices for rural Tororo are 0.2148 and 0.1116 , respectively. Despite similar estimated headcount indices in eastern Uganda and Tororo, the poverty depth estimates suggest that the rural population in Tororo is farther below the poverty line than the rural population in the eastern region as a whole. The estimated poverty depth translates to an average poverty gap of approximately $\$ 0.27$ per day at 2005 PPP. Comparing the two estimates of poverty severity further reveals that the poorest in Tororo district falls farther below the international poverty line on average than the poorest in the eastern region.

\subsection{Simulations of poverty reductions from $C A$ adoption}

Change in annual farm profits is added to predicted consumption values and poverty indices are re-simulated to assess the potential of CA adoption to reduce rural poverty in Tororo district. Six scenarios are considered by combining two measures of profitability and three levels of CA adoption. An increase in per-acre profit of 1,500 UGX (0.60 USD) per-season could decrease the incidence of rural poverty in Tororo district by one-tenth of a percentage point assuming that poor households adopt CA on one acre (table 3). If CA practices were implemented on 50 and 75 percent of cultivated land, which corresponds to 1.43 acre and 2.14 acres on average, the poverty headcount would decrease by 0.17 and 0.26 percentage points. A 1.1 percentage point reduction in the incidence of rural poverty could be achieved with a per-acre profit increase of 9,000 UGX (3.60 USD) per-season and CA adoption on half of poor households' cultivated land. Under this scenario, poverty depth and severity for rural Tororo would decrease by 0.0147 and 0.0112 . While magnitudes of the poverty impacts are relatively modest, they are based on the assumptions of no yield gain and conservative reductions in production costs. Overtime practicing CA is expected to increase yields as soil fertility and 
moisture content continue to improve. Therefore, the full economic benefits of CA adoption might not be realized until several years (10 to 20 years) of continued adoption.

Village focus group discussions revealed substantial heterogeneity in typical land preparation costs. The majority of cost estimates for land preparation by oxen on land typically used for maize cultivation were within a range of 30,000 UGX (11.98 USD) to 100,000 UGX (39.93 USD) per acre per ploughing. Thus, the potential for a locally adapted CA to reduce rural poverty in the district depends largely on saving costs currently being incurred by poor households under the conventional practice of land preparation. If tillage costs being paid by poor households are high, adoption of CA can generate a substantial reduction in Tororo's rural poverty. If poor household tillage costs are below the average focus group estimates, however, CA would not be profitable in the short-run.

\section{Conclusion}

Results from the SAE analysis can be used as a benchmark to assess development progress. This study's assessment of "best case" scenarios suggests that measurable rural poverty reduction could be achieved via relatively modest increases in the profit per-acre of poor households. Profit increases of 9,000 UGX (3.60 USD) per-acre per-season and 75 percent of the land area cultivated under CA would reduce the incidence of poverty by 1.8 percentage points. These gains are well within estimates of yield gains from maize CA practices in other parts of Africa (e.g. Abdulai, 2016; Jaleta et al., 2016). The potential for measurable poverty reduction via this relatively small increase in the farm profits of poor households should be encouraging to the district's researchers and project implementers whose work aims to reduce poverty.

While these district targets could be achieved with locally adapted CA, the technology's 
ability to reduce poverty is constrained by the lack of significant short-term yield gains from the system and the heterogeneity in land preparation costs faced by households. In the absence of short-term yield gains, the profit increases from CA adoption will only accrue to those households facing high tillage costs. These results suggest that there is more work to be done if CA development is to achieve its aim of poverty reduction. At the present state of CA development, achieving rural poverty reduction in Tororo from CA adoption may require policy incentives that improve the technology's short-term profitability relative to current farmer practices, such as subsidizing mucuna seeds and herbicide.

Along with these context-specific insights, the method applied in this study could easily be adapted to other settings. The collection of detailed consumption data for welfare analysis may be outside the budget and time constraints of many researchers and project implementers. Detailed datasets of household-level consumption data, however, are available from the World Bank's LSMS. By utilizing these publically available datasets and applying SAEp method to survey data such as those collected in this study, researchers can conduct welfare analysis for small geographic areas at low cost. Only the covariates used in the welfare analysis have to be added to the household survey. This allows researchers to conduct detailed welfare analysis while focusing their efforts (and budget) on other research questions of interest. 


\section{References}

Abdulai, A. N. 2016. Impact of conservation agriculture technology on household welfare in Zambia. Agri. Econ. 47, 729-741.

Christiaensen, L., Lanjouw, P., Luoto, J., Stifel, D., 2012. Small area estimation-based prediction methods to track poverty: Validation and applications. J. Econ. Inequal. 10(2), 267-297.

Cuong, N. V., 2011. Poverty projection using a small area estimation method: Evidence from Vietnam. J. Compar. Econ. 39(3), 368-382.

Dang, H.-A., Lanjouw, P. F., Serajuddin, U., 2014. Updating poverty estimates at frequent intervals in the absence of consumption data: Methods and illustration with reference to a middle-income country. Policy Research Working Paper no.7043. World Bank, Washington D.C.

Daniels, L., 2011. Measuring poverty trends in Uganda with non-monetary indicators. Accessed December 2016, available at http://www.fao.org/fileadmin/templates/ess/pages/rural/wye_city_group/2011/documents /session3/Daniels - Paper.pdf.

Deaton, A., Zaidi, S., 2002. Guidelines for constructing consumption aggregates for welfare analysis. Living Standards Measurement Study (LSMS) Working Paper no. 135. World Bank, Washington D.C.

Elbers, C., Lanjouw, J. O., Lanjouw, P., 2002. Micro-level estimation of welfare. Policy Research Working Paper no. 2911. World Bank, Washington D.C.

Elbers, C., Lanjouw, J. O., Lanjouw, P., 2003. Micro-level estimation of poverty and inequality. Econometrica. 71(1), 355-364.

Elbers, C., Lanjouw, P. F., Leite, P. G., 2008. Brazil within Brazil: Testing the Poverty Map Methodology in Minas Gerais. Policy Research Working Paper no 4513. World Bank, Washington D.C.

Greene, W. H., 2012. Econometric Analysis: Seventh Edition. Pearson Education Limited Essex, England.

Jaleta, M., M. Kassie, K. Tesfaye, T. Teklewold, P. Ranjan Jena, P. Marenya, O. Erenstein, 2016. Resource saving and productivity enhancing impacts of crop management innovation packages in Ethiopia. Agri. Econ. 47, 513-522.

Kijima, Y., Lanjouw, P. F., 2003. Poverty in India during the 1990s: a regional perspective. Policy Research Working Paper no. 3141. World Bank, Washington D.C.

Mason, N., Smale, M. 2013. Impacts of subsidized hybrid seed on indicators of economic wellbeing among smallholder maize growers in Zambia. Agri. Econ. 44, 659-670.

Okwi, P., Emwanu, T., Hoogeveen, J., 2003. Poverty and Inequality in Uganda: Evidence from Small Area Estimation Techniques. Accessed December 2016, available at http://africainequalities.org/wp-content/uploads/2016/07/Poverty-and-Inequality-inUganda-Evidence-from-Small-Area-Estimation-Techniques.pdf.

Pape, U., Mistiaen, J., 2015. Measuring Household Consumption and Poverty in 60 minutes: The Mogadishu High Frequency Survey. Accessed December 2016, available at http://cega.berkeley.edu/assets/miscellaneous files/82-ABCA_PapeMistiaen.pdf.

Ravallion, M., Chen, S., Sangraula, P., 2009. Dollar a day revisited. World Bank Econ. Rev. 23(2), 163-184.

SANREM, 2013. Feed the Future SANREM Innovation Lab Annual Report 2013. Accessed December 2016, available at http://www.oired.vt.edu/sanremcrsp/wpcontent/uploads/2013/03/SANREM-2013AnnualReport.pdf. 
Stevenson, J. R., Serraj, R., Cassman, K. G., 2014. Evaluating conservation agriculture for smallscale farmers in Sub-Saharan Africa and South Asia. Agri. Ecosyst. Environ. 187, 1-10.

Stifel, D., Christiaensen, L., 2007. Tracking poverty over time in the absence of comparable consumption data. World Bank Econ. Rev. 21(2), 317-341.

Tarozzi, A., Deaton, A., 2009. Using census and survey data to estimate poverty and inequality for small areas. Rev. Econ. Stat. 91(4), 773-792.

UBOS, 2013. Uganda National Panel Survey 2011/12 Accessed December 2016, available at http://siteresources.worldbank.org/INTLSMS/Resources/3358986-

$1233781970982 / 5800988-1265043582346 / 6752587-$ 1388762908476/UNPS Report Wave3.pdf.

UBOS, 2014. Uganda National Population and Housing Census: Provisional Results. Accessed December 2016, available at http://unstats.un.org/unsd/demographic/sources/census/wphc/Uganda/UGA-2014-11.pdf.

Vaiknoras, K., Norton, G., Alwang, J., 2015. Farmer preferences for attributes of conservation agriculture in Uganda. AfJARE. 10(2), 158-173.

World Bank, 2015. Living Standards Measurement Study Dataset Finder. Accessed September 2015, available at http://iresearch.worldbank.org/lsms/lsmssurveyFinder.htm.

World Bank, 2016a. Consumer price index. Accessed December 2016, available at http://data.worldbank.org/indicator/FP.CPI.TOTL.

World Bank, 2016b. PPP conversion factor, private consumption (LCU per international \$). Accessed December 2016, available at http://data.worldbank.org/indicator/PA.NUS.PRVT.PP?page=1.

Zeller, M., A. Diagne \& C. Mataya (1998). "Market access by smallholder farmers in Malawi: Implications for technology adoption, agricultural productivity and crop income", Agri. Econ. 19 (1-2), 219-229

Zeng, D., J. Alwang, G.W. Norton, B. Shiferaw, M. Jaleta \& C. Yirga (2015). "Ex-post impacts of improved maize varieties on poverty in rural Ethiopia", Agri. Econ. 46(4), 515-526. 


\section{Tables}

Table 1. Rural FGT Poverty Indices Estimates

\begin{tabular}{|c|c|c|c|c|c|c|c|c|}
\hline \multirow{3}{*}{$\begin{array}{l}\text { FGT Poverty } \\
\text { Index }\end{array}$} & \multicolumn{4}{|c|}{ Eastern Region } & \multicolumn{4}{|c|}{ Tororo District } \\
\hline & \multirow{2}{*}{ Estimate } & \multirow{2}{*}{$\begin{array}{l}\text { Std. } \\
\text { Dev }\end{array}$} & \multicolumn{2}{|c|}{$\begin{array}{l}\text { 95\% Confidence } \\
\text { Interval }\end{array}$} & \multirow[t]{2}{*}{ Estimate } & \multirow{2}{*}{$\begin{array}{l}\text { Std. } \\
\text { Error }\end{array}$} & \multicolumn{2}{|c|}{$\begin{array}{l}\text { 95\% Confidence } \\
\text { Interval }\end{array}$} \\
\hline & & & Lower & Upper & & & Lower & Upper \\
\hline Headcou & 0.5627 & 0.0340 & 0.4946 & 0.6308 & 0.5649 & 0.0445 & 0.4762 & 0.6508 \\
\hline Depth & 0.1758 & 0.0189 & 0.1379 & 0.2137 & 0.2148 & 0.0248 & 0.1684 & 0.2644 \\
\hline Severity & 0.0751 & 0.0123 & 0.0505 & 0.0997 & 0.1116 & 0.0163 & 0.0826 & 0.1457 \\
\hline
\end{tabular}

Note: The Eastern Region's rural poverty indices are estimated using the household consumption per capita aggregates from the LSMS-ISA, the adjusted international poverty line, and Stata's svy estimation commands for survey data. The Tororo District's rural indices are estimated by applying the SAEp technique to the THS. The poverty line is $\$ 1.25$ per capita per day (at 2005 PPP) adjusted to 2012 Ugandan shillings. 
Table 2. Regression Results for the FGLS Model of Logged Household Consumption Expenditure per Capita (Equation 3)

\section{Variables}

Household size

Proportion of household members under 16 years

Household has an improved (non-mud) floor $(\mathrm{yes}=1 ;$ no $=0)$

Household's main source of drinking water is an unprotected well, spring,

river, or lake (yes $=1$; no $=0$ )

Number of cell phones owned

Number of motorcycles owned

Household has electricity $($ yes $=1 ;$ no $=0$ )

Number of household members whose highest education level completed is primary school

Number of male household members whose highest education level completed is some secondary school

Number of female household members whose highest education level completed is some secondary school

Number of male household members whose highest education level completed is secondary school or above

Number of female household members whose highest education level completed is secondary school or above

Number of agricultural acres owned

Number of pigs owned

Constant

$\mathrm{N}$

$\mathrm{R}^{2}$

Adjusted $\mathrm{R}^{2}$
Coefficient Estimates

$-0.078 * * *$

(0.177)

$0.166^{* *}$

(0.066)

$-0.385^{* * *}$

(0.141)

$0.094 * * *$

$(0.022)$

$0.312 * * *$

(0.081)

$0.542 * * *$

$(0.125)$

0.017

$(0.031)$

$0.150 * * *$

0.060

(0.047)

$0.233 * *$

(0.094)

$0.275 * *$

(0.109)

$0.021 * * *$

(0.003)

$0.058 * * *$

$(0.012)$

13.611 ***

(0.096)

559

0.469

0.455

Note: Coefficients were estimated by FGLS with individual sampling weights. Village-level cluster robust standard errors are in parentheses. Statistical significance at the $10 \%, 5 \%$, and $1 \%$ levels is denoted by one, two, and three asterisks respectively. 
Table 3. Estimated Reductions in the Poverty Indices for Different Levels of Per-Acre Profit Changes and Land Cultivated by Poor Households

\begin{tabular}{|c|c|c|c|c|c|c|}
\hline $\begin{array}{l}\text { Per-Acre Profit } \\
\text { Change (UGX) }\end{array}$ & & 1,500 & & & 9,000 & \\
\hline Land under CA & 1 acre & $50 \%$ & $75 \%$ & 1 acre & $50 \%$ & $75 \%$ \\
\hline \multicolumn{7}{|l|}{ Poverty impacts } \\
\hline$\Delta$ Headcount & -0.0010 & -0.0017 & -0.0026 & -0.0064 & -0.0114 & -0.0181 \\
\hline$\Delta$ Depth & -0.0017 & -0.0025 & -0.0037 & -0.0099 & -0.0147 & -0.0217 \\
\hline$\Delta$ Severity & -0.0014 & -0.0020 & -0.0030 & -0.0081 & -0.0112 & -0.0162 \\
\hline
\end{tabular}


Figure 1. Cumulative Distribution Function of Predicted Annul Household Consumption Per Capita for Rural Tororo District using SAEp Method

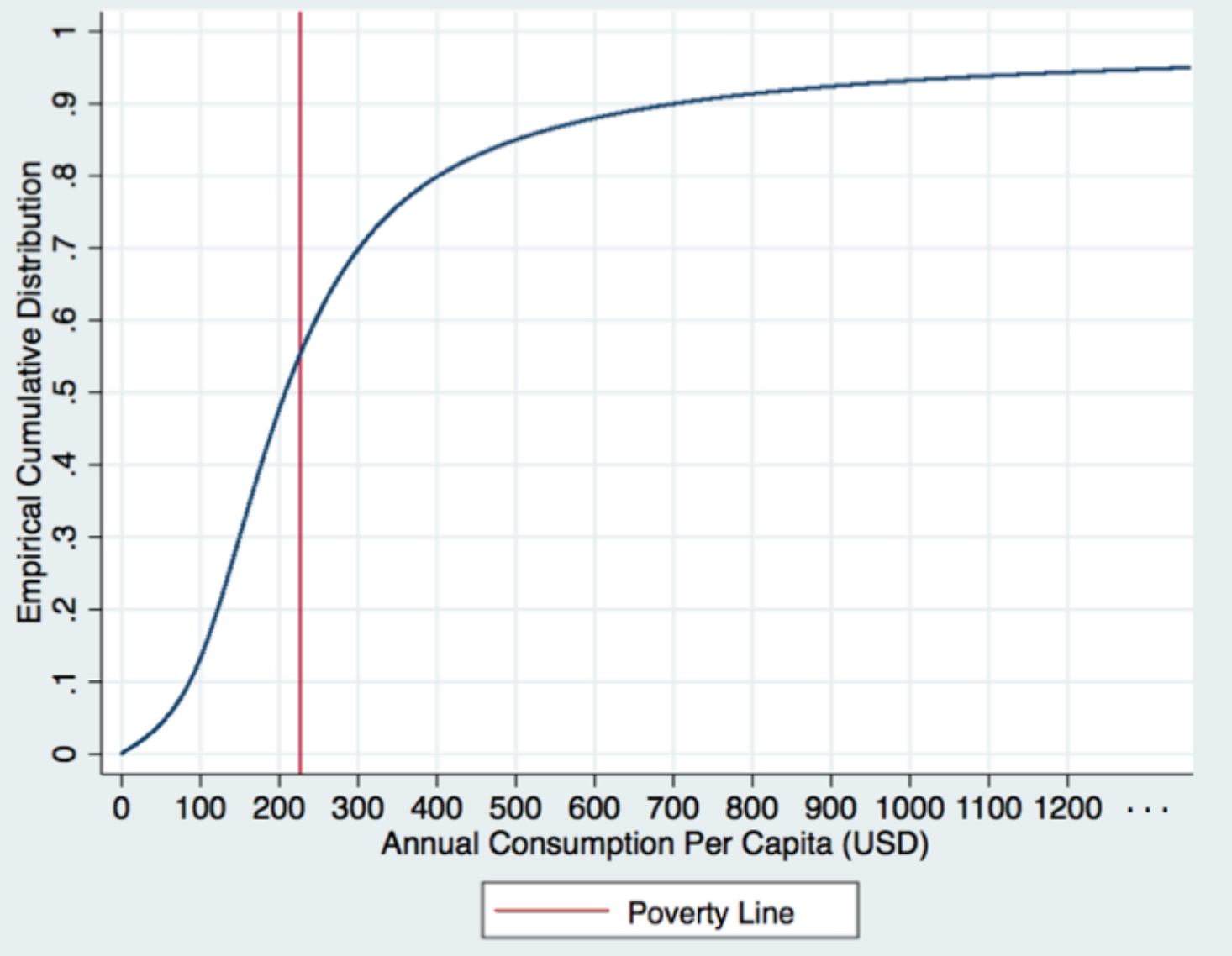

